\title{
Changes in prevalence and load of airway bacteria using quantitative PCR in stable and exacerbated COPD
}

\author{
Davinder S Garcha, ${ }^{1}$ Sarah J Thurston, ${ }^{1}$ Anant R C Patel, ${ }^{1}$ Alexander J Mackay, ${ }^{1}$ \\ James J P Goldring, ${ }^{1}$ Gavin C Donaldson, ${ }^{1}$ Timothy D McHugh, ${ }^{2}$ Jadwiga A Wedzicha ${ }^{1}$
}

\begin{abstract}
- An additional appendix is published online only. To view this file please visit the journal online (http://dx.doi.org/10 1136/thoraxjnl-2012-201924).

${ }^{1}$ Centre for Respiratory Medicine, University College London, London, UK

${ }^{2}$ Centre for Clinical

Microbiology, University College London, London, UK
\end{abstract}

\section{Correspondence to}

Davinder S Garcha, Centre for Respiratory Medicine, University College London, London NW3 2PF, UK;

davinder.garcha.09@ucl.ac.uk

Received 18 March 2012 Accepted 10 July 2012 Published Online First 27 July 2012

\section{ABSTRACT}

Background Prevalence and load of airway bacteria in stable and exacerbated chronic obstructive pulmonary disease (COPD) has been previously studied using microbiological culture. Molecular techniques, such as quantitative PCR (qPCR), may be more informative.

Methods In this study, 373 sputum samples from 134 COPD outpatients were assessed for prevalence and load of typical airway bacteria (Haemophilus influenzae, Streptococcus pneumoniae, Moraxella catarrhalis) by multiplex qPCR, with 176 samples analysed for atypical bacteria. Paired stable and exacerbation typical bacteria data were compared in 52 patients. We compared routine culture with qPCR in 177/373 samples.

Results Typical bacteria were more prevalent in exacerbation than stable-state paired samples: 30/52 $(57.7 \%)$ vs. $14 / 52$ (26.9\%); $p=0.001$. In patients who were bacteria-positive at both time points, mean ( \pm 1 SEM) load was significantly higher at exacerbation than stable state $\left(10^{8.5( \pm 0.3)}\right.$ vs. $\left.10^{7.2( \pm 0.5)} \mathrm{cfu} / \mathrm{ml}\right)$, constituting a 20 -fold increase $(p=0.011)$. qPCR was more discriminatory at detecting typical bacteria than microbiological culture (prevalence $59.3 \%$ vs. $24.3 \%$; $\mathrm{p}<0.001)$. At stable state, higher airway bacterial load correlated with more severe airflow limitation (FEV ${ }_{1} \%$ predicted) ( $r=-0.299 ; p=0.033)$ and higher inhaled corticosteroid dosage $(r=0.382 ; p=0.008)$. Mean C-reactive protein was higher in bacterial-associated exacerbations (35.0 Vs $25.1 \mathrm{mg} / \mathrm{L} ; p=0.032$ ).

Conclusions Airway bacterial prevalence and load increase at COPD exacerbations and are an aetiological factor. qPCR is more discriminatory than culture, identifying higher airway bacterial prevalence. Exacerbations associated with bacterial detection showed a higher mean C-reactive protein level. In the stable state, airway bacterial load is related to more severe airflow limitation and higher inhaled corticosteroid dosage used.

\section{INTRODUCTION}

Chronic obstructive pulmonary disease (COPD) is an inflammatory condition caused by an abnormal response to noxious gases and particles. ${ }^{1}$ COPD is associated with considerable morbidity and mortality and has been projected to become the fourth highest cause of death by $2030 .^{2}$ Acute exacerbations of COPD are episodes which are characterised by a worsening of respiratory symptoms associated with variable degrees of physiological

\section{Key messages}

What is the key question?

- Is there a change in prevalence and load of airway bacteria in COPD patients between the stable state and exacerbation, and what is the association between bacteria and lung function, inhaled corticosteroid dosage and systemic inflammation?

\section{What is the bottom line?}

- Airway bacterial prevalence and load, as detected by $\mathrm{qPCR}$, increases significantly at COPD exacerbation, with quantitative molecular techniques offering a more accurate reflection of prevalence and load compared with conventional methods. Higher bacterial load is correlated with poorer lung function and higher inhaled corticosteroid dosage in stable COPD patients; bacterial presence at exacerbation is associated with higher systemic inflammation.

\section{Why read on?}

- Increased airway bacterial load is a key aetiological factor in acute exacerbations of COPD, and also relates to disease severity in the stable state. Inhaled corticosteroid usage may affect bacterial colonisation, and thus increase susceptibility to pneumonia.

deterioration. ${ }^{3}$ These events are a major cause of morbidity and mortality globally, and COPD exacerbations are a leading cause of hospital admissions. ${ }^{3}$

Lower airway bacterial colonisation (LABC) is a common and important feature of COPD, and the commonly isolated organisms are $S$ pneumoniae, $H$ influenzae and $M$ catarrhalis, ${ }^{4}{ }^{5}$ although most studies investigating $\mathrm{LABC}$ have used culture techniques. $\mathrm{LABC}$ has been shown to be related to an increase in airway inflammation, exacerbation frequency and lung function decline. ${ }^{5-8}$

Previous studies suggest that the majority of exacerbations have an infectious aetiology-with approximately half these events associated with culture of potentially pathogenic airway bacteria, similar to those found in the stable state. ${ }^{9}$ Positive cultures of Pseudomonas aeruginosa have also been shown to be associated with COPD, but more commonly in advanced disease. ${ }^{10}$ 
To date, the vast majority of analysis of bacterial prevalence and load has been based on culture, but there is little on PCR comparison with culture. The use of culture-independent techniques, such as quantitative PCR (qPCR), has not been extensively studied in the context of atypical airway bacteria, which are characteristically difficult to culture (C pneumoniae, L pneumophila and $M$ pneumoniae), with one previous study showing no association with COPD exacerbations. ${ }^{11}$ Conversely, serological analysis has suggested an association, ${ }^{12} 13$ and further examination is warranted.

The objective of this study was to investigate the prevalence and load of typical and atypical airway bacteria in COPD using modern molecular techniques. We also analysed prevalence and load at the stable and exacerbation states, and compared qPCR with routine microbiological culture.

\section{METHODS}

\section{Recruitment criteria}

This study involved 134 subjects enrolled in the London COPD cohort between January 2007 and March 2011. The patients form part of a rolling cohort used to prospectively investigate the mechanisms and aetiology of COPD exacerbations, as previously described by our group. ${ }^{14}$ Patients were included if the forced expiratory volume in one second $\left(\mathrm{FEV}_{1}\right)$ was $\leq 80 \%$ predicted and $\mathrm{FEV}_{1}$ /forced vital capacity (FVC) ratio was $<0.7$, in keeping with GOLD stages II-IV. ${ }^{1}$ A history of chronic symptoms (dyspnoea, sputum production, wheeze and cough) was taken, as well as smoking history (number of pack-years smoked, current smoking status). Patients with a history of any other significant respiratory diseases were excluded, as were those unable to complete daily diary cards.

\section{Definitions of clinical states}

An exacerbation was defined as new or increased respiratory symptoms for two or more consecutive days, with at least one major symptom (dyspnoea, sputum purulence and sputum volume), and another major or a minor symptom (wheeze, cold, sore throat and cough), the first day of which was defined as the day of onset of the exacerbation. Stable state was defined as no symptom-defined exacerbations for the preceding 4 weeks and the subsequent 2 weeks post-clinic visit.

\section{Clinical assessment}

Spirometry was performed in accordance with ATS/ERS guidelines, using a volumetric storage spirometer (Vitalograph 2160, Maids. Moreton, Buckingham, UK). FEV 1 was expressed as a percentage of that predicted from age, height and sex. Serum C-reactive protein (CRP) quantification was performed to assess systemic inflammation, using Modular Analytics E 170 Module (Roche, Burgess Hill, UK). Patients recorded inhaled corticosteroid dosage and usage daily on diary cards. Due to variations in dosage by different medications, we applied beclomethasoneequivalence dosage correction, as previously performed by our group. ${ }^{15}$

\section{Sputum collection and processing}

Sputum was spontaneously expectorated into a sterile pot in the stable state and/or at exacerbation. All exacerbation visits occurred within 7 days of exacerbation symptom onset. Patient samples were used in a number of different analyses (figure 1).

Following expectoration, sputum plugs were separated from saliva using sterile forceps, with one-third being taken for culture analysis where there was sufficient quantity. The

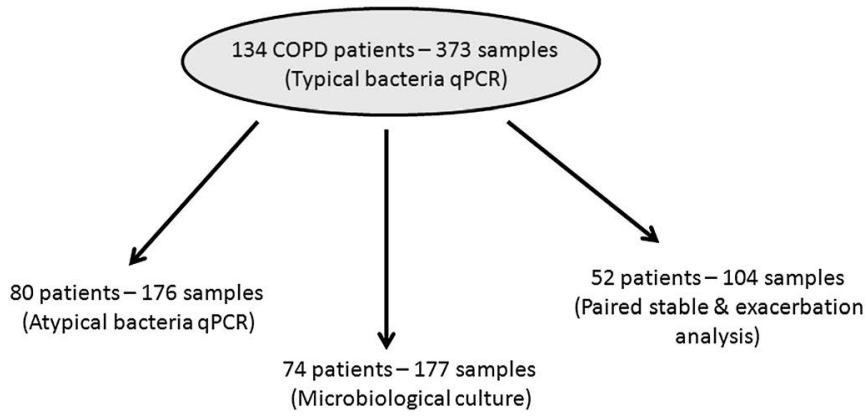

Figure 1 COPD patient groups analysed. Patients may have been in more than one subanalysis. For paired analysis, stable samples were obtained $<365$ days prior to exacerbation (the nearest stable sample to the exacerbation was used).

remaining sputum was weighed and suspended in nine times volume of standard isotonic phosphate-buffered saline (PBS). Glass beads were added to this suspension and it underwent homogenisation by vortexing for $15 \mathrm{~s}$, rocking for $15 \mathrm{~min}$ (IKA Vibrax VXR, Staufen, Germany) and additional vortexing for $15 \mathrm{~s}$. Aliquots of $500 \mu \mathrm{l}$ were taken for storage at $-80^{\circ} \mathrm{C}$ for subsequent batch processing.

\section{Routine microbiological culture}

Qualitative bacterial culture was carried out by the Department of Medical Microbiology, Royal Free Hampstead NHS Trust, London. Briefly, sputum was cultured onto suitable agar for $24 \mathrm{~h}$ at $37^{\circ} \mathrm{C}$ and $5 \% \mathrm{CO}_{2}$. Agar types used were Columbia blood agar (general growth media), Chocolate agar (growth of fastidious bacteria), MacConkey agar (growth of Gram-negative bacteria), and COBA agar (growth of Streptococcus spp.). S pneumoniae was identified through optochin sensitivity testing.

\section{DNA extraction}

Homogenised sputum samples underwent heat-kill treatment at $90^{\circ} \mathrm{C}$ for $30 \mathrm{~min}$ before being microfuged at $13000 \mathrm{~g}$ for $10 \mathrm{~min}$. The pellet was washed in $1 \mathrm{ml} \mathrm{PBS}$ and spun at $13000 \mathrm{~g}$ for $10 \mathrm{~min}$ before removal of supernatant and re-suspension of the pellet in $200 \mu \mathrm{l}$ of PCR-grade UV-sterilised water (SigmaW4502). To each sample, $200 \mu \mathrm{l}$ of $10 \%$ Chelex 100 (Sigma C7901) was added. Samples were incubated for $20 \mathrm{~min}$ in a heat block at $56^{\circ} \mathrm{C}$. Samples were heated at $95^{\circ} \mathrm{C}$ for five minutes prior to cooling on ice. Samples were then spun in a microfuge at $16000 \mathrm{~g}$ for $10 \mathrm{~min}$. Supernatant, containing extracted DNA, was transferred to a fresh UV-sterilised $1.5 \mathrm{ml}$ tube and stored at $4^{\circ} \mathrm{C}$.

\section{Multiplex qPCR detection of bacteria}

Real-time multiplex qPCR was performed on $S$ pneumoniae, $H$ influenzae and $M$ catarrhalis, targeting Spn9802 (gene fragment), $H$ influenzae P4 lipoprotein gene, and copB outer-membraneprotein gene, respectively. Both Spn $9802^{16}$ and cop $B^{17}$ profiles used previously validated qPCR primers and probes, ensuring no crossreactivity with related oral species. The $H$ influenzae P4 lipoprotein gene target was established in-house. This was confirmed to have no cross-reactivity with other Haemophilus species as well as a number of Streptococcus spp., $M$ catarrhalis, Bordatella pertussis, Candida spp., P aeruginosa, Escherichia coli, Neisseria meningitidis, Acinetobacter spp., Legionella pneumoniae, Klebsiella pneumoniae, methicillin-resistant Staphylococcus aureus and Corynebacterium diphtheriae. An internal amplification control (IAC), targeting the 
Table 1 Stable-state clinical characteristics of COPD patient subgroups

\begin{tabular}{|c|c|c|c|c|c|}
\hline & \multicolumn{5}{|c|}{ COPD patient subgroups } \\
\hline & $\begin{array}{l}\text { Typical bacteria } \\
\text { analysis }(n=134)\end{array}$ & $\begin{array}{l}\text { Culture analysis } \\
(n=74)\end{array}$ & $\begin{array}{l}\text { Atypical bacteria } \\
\text { analysis }(\mathrm{n}=\mathbf{8 0})\end{array}$ & $\begin{array}{l}\text { Paired analysis } \\
(n=52)\end{array}$ & p Value \\
\hline $\mathrm{FEV}_{1}(\mathrm{I})$ & $1.22( \pm 0.52)$ & $1.20( \pm 0.5)$ & $1.11( \pm 0.50)$ & $1.15( \pm 0.50)$ & 0.407 \\
\hline $\mathrm{FEV}_{1} / \mathrm{FVC}(\%)$ & $45.8( \pm 12.9)$ & $45.2( \pm 12.6)$ & $43.8( \pm 13.4)$ & $43.4( \pm 13.4)$ & 0.596 \\
\hline Predicted $\mathrm{FEV}_{1}(\%)$ & $48.5( \pm 18.1)$ & $48.5(18.3)$ & $45.4( \pm 17.8)$ & $46.4( \pm 17.5)$ & 0.582 \\
\hline Current smoker (\%) & 28 & 32 & 25 & 29 & 0.860 \\
\hline Age (years) & $69.8( \pm 8.7)$ & $69.8( \pm 8.3)$ & $70.1( \pm 8.9)$ & $68.7( \pm 8.5)$ & 0.840 \\
\hline Male sex (\%) & 64 & 69 & 68 & 61 & 0.773 \\
\hline Pack years smoking & $52.5( \pm 34.6)$ & $55.9( \pm 38.2)$ & $57.1( \pm 34.9)$ & $42.8( \pm 24.2)$ & 0.118 \\
\hline
\end{tabular}

PhyB gene of Solanum tuberosum, was used in order to detect any PCR inhibition, incorporated in the PCR mastermix. ${ }^{18}$ The following positive control strains were used: $S$ pneumoniae ATCC strain 49619; H influenzae ATCC strain 10211; M catarrhalis ATCC strain 25238. The minimum limit of detection used in this study was $10^{4}$ colony-forming units $(\mathrm{cfu}) / \mathrm{ml}$.

A separate multiplex qPCR was performed to detect $C$ pneumoniae, $L$ pneumophila and $M$ pneumoniae, targeting RNApolymerase $\beta$-chain gene, MIP gene and P1 adhesin protein gene, respectively. $C$ pneumoniae primer/probe set was a previously validated set. ${ }^{19}$ M pneumoniae and $L$ pneumophila were developed in-house and shown to have no cross-reactivity with related species and other oral flora. The PCR was performed with two types of mastermix, one of which was spiked with an IAC (L pneumophila DNA). Primer and probe details are listed in webonly files in the appendix. Normalisation of qPCR results was performed by correcting $\mathrm{C}$ t values of the IAC in positive samples according to its corresponding value in no-template-control samples.

\section{Statistical analysis}

Data were analysed using PASW Statistics V.18 (SPSS Inc.). The Kolmogorov-Smirnov test for normality was applied. Clinical data with normal distribution are described in mean $( \pm S D)$. Differences between groups were analysed by independentsamples $t$ test, paired-samples t test, Mann-Whitney $U$ test or one-way ANOVA, dependent upon the sample population being investigated. Relationships between continuous variables were analysed using Pearson's or Spearman's correlation in a univariate analysis, or by linear regression in a multivariate analysis. Frequency distribution was explored by $\chi^{2}$ analysis. A probability of $p<0.05$ was considered to be statistically significant.

\section{Ethical considerations}

The study was approved by the Royal Free Research Ethics Committee, and all patients gave informed written consent.

\section{RESULTS}

\section{Patient characteristics}

Sputum samples from 134 COPD patients were examined. There were no clinically or statistically important differences in stablestate clinical characteristics between the subgroups (table 1).

\section{Typical bacteria prevalence and load determined by qPCR}

Typical bacterial prevalence by qPCR was higher in exacerbation sputum samples compared with stable samples (74/131 bacterial isolates $(56.5 \%)$ vs $107 / 242(44.2 \%)$ respectively, $\mathrm{p}=0.024)$.
In samples positive for bacteria, mean ( \pm 1 SEM)-typical bacteria count was significantly higher during exacerbation, at $10^{8.3( \pm 0.2)} \mathrm{cfu} / \mathrm{ml}$ (in absolute numbers $2 \times 10^{8} \mathrm{cfu} / \mathrm{ml}$ ), compared with the stable state, with $10^{7.3( \pm 0.2)} \mathrm{cfu} / \mathrm{ml}$ (in absolute numbers $\left.2 \times 10^{7} \mathrm{cfu} / \mathrm{ml}\right)$, a 10 -fold increase, and significantly different $(\mathrm{p}<0.001)$ in an unpaired analysis (figure 2). H influenzae was the most prevalent species, both in the stable state $(21.9 \%)$ and at exacerbation (26.0\%). $M$ catarrhalis was significantly more prevalent at exacerbation (16.8\%) compared with the stable state $(7.4 \%)(p=0.005)$. Mean ( \pm 1 SEM) bacterial load of both $S$ pneumoniae and $H$ influenzae was significantly higher at exacerbation than at stable state: $10^{8.1( \pm 0.3)}$ vs $10^{7.2( \pm 0.3)} \mathrm{cfu} / \mathrm{ml}, \mathrm{p}=0.043$ and $10^{8.2( \pm 0.2)}$ vs $10^{7.0( \pm 0.2)} \mathrm{cfu} / \mathrm{ml}, \mathrm{p}<0.001$, respectively.

\section{Typical bacteria prevalence and load in paired stable and exacerbation samples}

Fifty-two pairs of stable and exacerbation samples from 52 patients showed significantly higher cumulative prevalence of typical bacteria at exacerbation compared with the stable state $(67.3 \%$ vs $30.8 \%$; $p 0.001)$. Fourteen stable-state samples (26.9\%) were positive for at least one bacterium compared with 30 exacerbation-state samples $(57.7 \%) \quad(p=0.001)$. In paired samples which were bacteria-positive at both stable and exacerbation state $(n=12)$, the mean load was approximately 20 -fold higher at exacerbation than in the stable sample $\left(10^{8.5( \pm 0.3)}\right.$ vs $\left.10^{7.2( \pm 0.5)} \mathrm{cfu} / \mathrm{ml}\right)(\mathrm{p}=0.011)$ (figure $3 \mathrm{~B}$ ).

The species detected with highest prevalence was $H$ influenzae at stable state $(11 / 52,21.2 \%)$, with $S$ pneumoniae most frequently

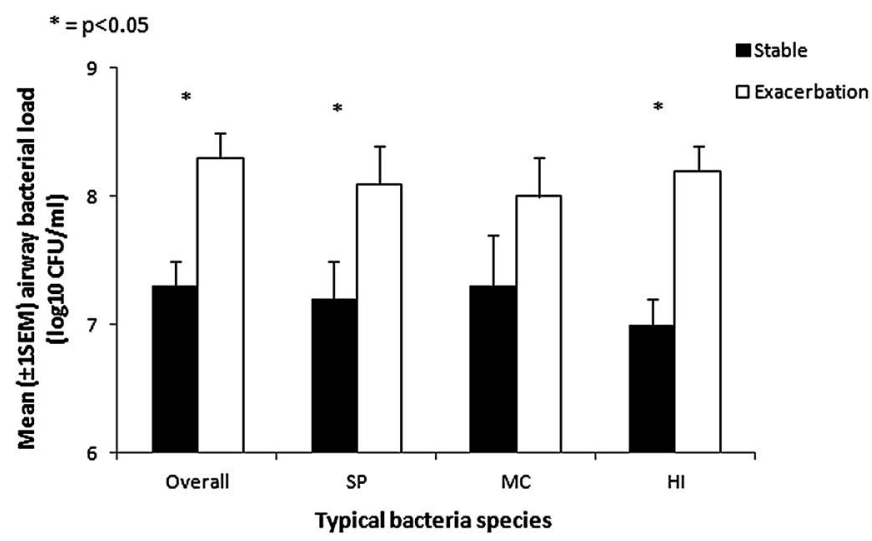

Figure 2 Quantitative PCR comparison of load of typical airway bacteria in stable COPD $(n=242)$ and exacerbation $(n=131)$ in unpaired samples. Species: $\mathrm{SP}=$ Streptococcus pneumoniae; $\mathrm{MC}=$ Moraxella catarrhalis, $\mathrm{HI}=$ Haemophilus influenzae. 
seen at exacerbation (13/52, 25\%) (figure 3A). $M$ catarhalis showed a significant increase in prevalence at exacerbation $(10 / 52$, $19.2 \%)$, increasing from $2 / 52(3.8 \%)$ at the stable state $(\mathrm{p}=0.014)$. $S$ pneumoniae prevalence was significantly higher at exacerbation $(13 / 52,25.0 \%)$ than during stable state $(3 / 52,5.8 \%)(p=0.002)$.

\section{Comparison of qPCR with culture for the detection of typical bacteria}

Culture and qPCR for typical bacteria were compared in 177 samples (105 stable and 72 exacerbation samples) from 74 patients.

qPCR was far more discriminatory at detecting typical bacteria than culture (105/177 positive samples (59.3\%), vs $43 / 177(24.3 \%), p<0.001)$. This finding was replicated in terms of individual bacterial species: $H$ influenzae 30.5\% PCR-positive versus $15.8 \%$ culture-positive, $(p=0.001)$; S pneumoniae $14.1 \%$ versus $5.1 \%,(p=0.004) ; M$ catarrhalis $14.7 \%$ versus $3.4 \%$, $(p<0.001)$ (figure 4$)$.

Positive culture identification and negative qPCR identification was seen for $H$ influenzae in $4 / 177$ samples (2.3\%); for $S$ pneumoniae in $4 / 177$ samples (2.3\%); for $M$ catarrhalis in $1 / 177$ samples $(0.6 \%)$.

Effect of typical bacteria on lung function in stable state and at exacerbation

Higher bacterial load was significantly correlated to disease severity in the stable state $\left(\mathrm{FEV}_{1} \%\right.$ predicted); $\mathrm{r}=-0.299$;

\section{A $\quad * p<0.05$}
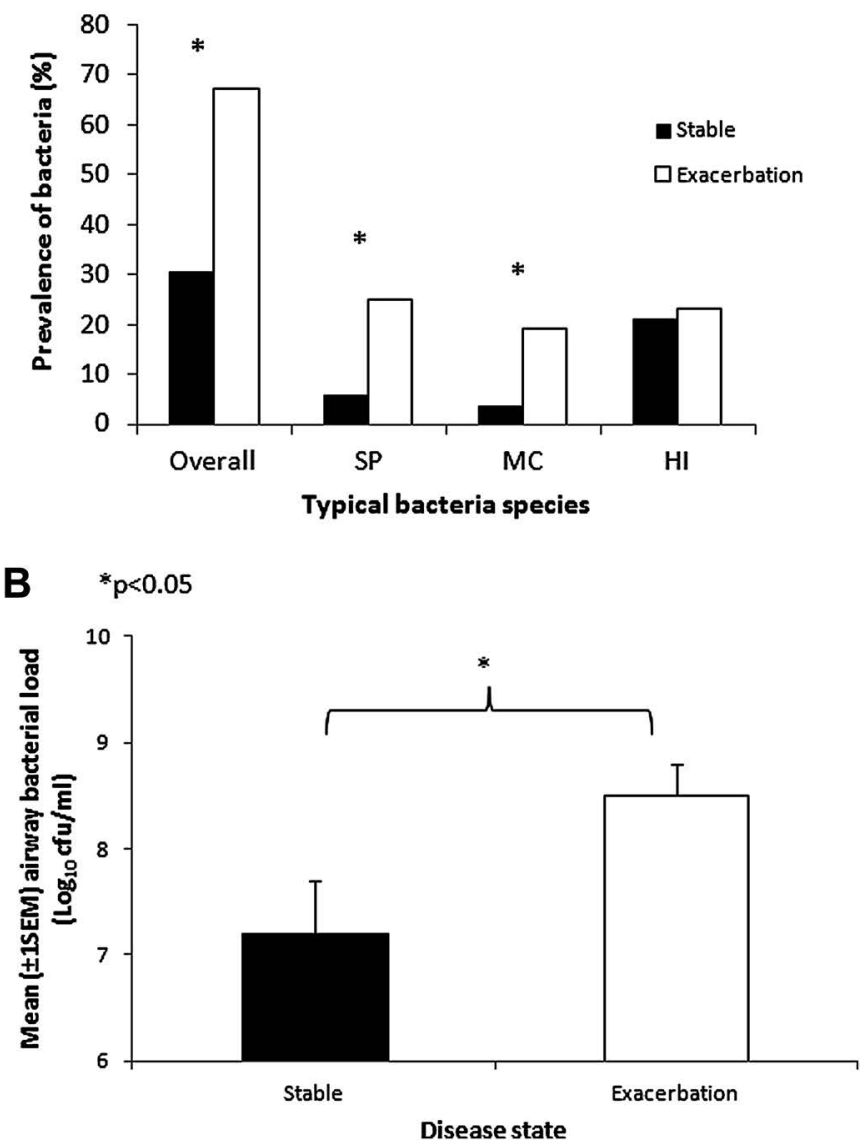

Figure 3 (A) Prevalence of typical airway bacteria in paired samples from COPD patients at both stable and exacerbation $(n=65)$. (B) Overall bacterial load at stable state and exacerbation, in patients positive for typical airway bacteria at both states $(n=12)$. Species:

$\mathrm{SP}=$ Streptococcus pneumoniae; $\mathrm{MC}=$ Moraxella catarrhalis

$\mathrm{HI}=$ Haemophilus influenzae.

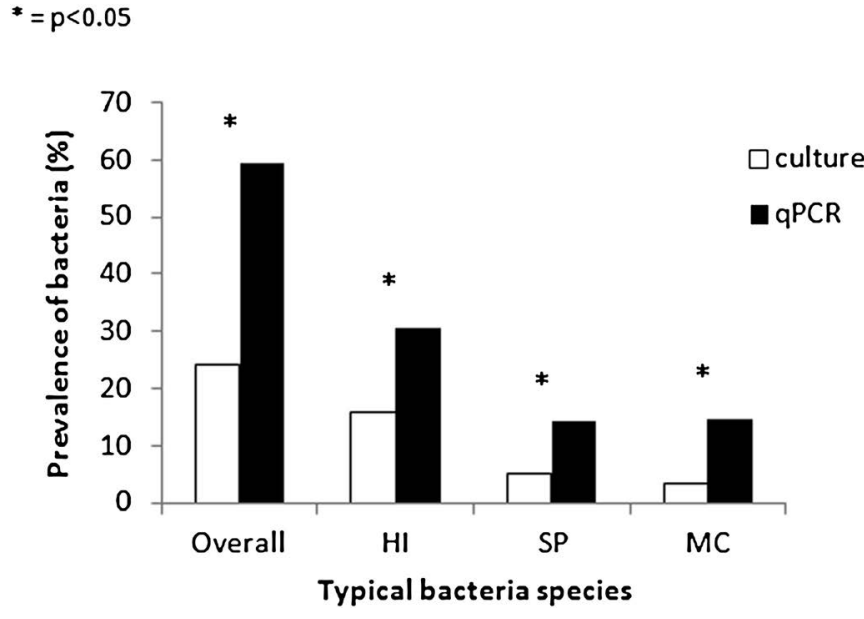

Figure 4 Comparison of culture and qPCR detection of three typical airway bacteria in sputa from 177 COPD patients (105 stable, 72 exacerbation). Species: $\mathrm{HI}=$ Haemophilus influenzae, $\mathrm{SP}=$ Streptococcus pneumoniae; $\mathrm{MC}=$ Moraxella catarrhalis.

$\mathrm{p}=0.033$ (figure 5). In a multivariate analysis, the relationship between $\mathrm{FEV}_{1}$ and airway bacterial load remains significant after allowance of either age $(p=0.036)$ or smoking status $(p=0.046)$, although it just misses statistical significance when both age and smoking status are included in the model $(p=0.057)$.

Percentage $( \pm \mathrm{SD})$ change in $\mathrm{FEV}_{1}$ (from stable state) with $H$ influenzae-associated exacerbations $(n=10)$ was $-17.4 \%( \pm 15.8 \%)$, and in exacerbations which had no $H$ influenzae presence $(n=47)$, the change was $-5.9 \%( \pm 20.0 \%)$. This difference was not statistically significant $(\mathrm{p}=0.09)$.

\section{Airway bacterial load association with inhaled corticosteroid usage}

Forty-seven (92.2\%) patients who had bacteria detected in the stable state had inhaled corticosteroid usage recorded. Median (IOR) beclomethasone-equivalent dosage was 2000 (6402000) $\mu$ g daily. In a univariate analysis, higher airway bacterial load was also significantly correlated to higher inhaled corticosteroid dosage (corrected for beclomethasone equivalence);

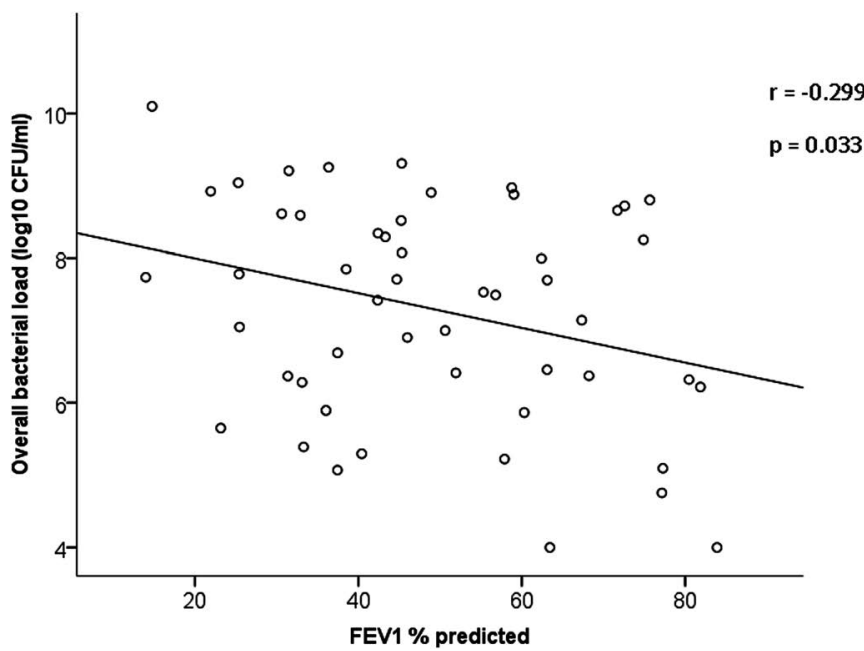

Figure 5 Association of bacterial load with $\mathrm{FEV}_{1}$ in stable colonised patients $(n=51)$. This illustrates the association of lower $\mathrm{FEV}_{1}$ status in patients with higher bacterial loads. Data with $\mathrm{FEV}_{1} \%$ predicted $>80 \%$ were from patients who had $\mathrm{FEV}_{1} \%$ predicted $<80 \%$ at recruitment. 
$r=0.382 ; p=0.008$. This relationship remains significant in a multivariate analysis including age, smoking status and $\mathrm{FEV}_{1}$ $\%$ predicted $(\mathrm{p}=0.022)$.

\section{Systemic inflammation is related to airway bacterial presence during exacerbations}

Levels of CRP, a marker of systemic inflammation, were significantly related to presence of typical airway bacteria at exacerbation. CRP was measured in 119 exacerbation samples. Exacerbations with bacterial detection $(n=58)$ showed significantly higher mean CRP compared with exacerbations with no bacterial detection $(n=61) ; 35.0$ versus $25.1 \mathrm{mg} / \mathrm{l}, \mathrm{p}=0.032$.

\section{Analysis of COPD patient samples for atypical bacteria}

A total of 176 samples, from 80 patients, were investigated for presence of the atypical bacteria (C pneumoniae, L pneumophila, $M$ pneumoniae). Of these, 97 were stable samples, and 79 were exacerbation samples. Five samples were positive for $L$ pneumophila (four stable, one exacerbation), and one stable sample was positive for $M$ pneumoniae. No relationship was observed between atypical bacterial load and clinical outcome: Mean bacterial load for $L$ pneumophila was $10^{4.4( \pm 0.4)}$, and for the $M$ pneumoniae sample it was $10^{7.4} \mathrm{cfu} / \mathrm{ml}$.

\section{DISCUSSION}

This is the largest study, to date, to use molecular techniques for detection of airway bacteria, and also the first to complimentarily evaluate typical and atypical bacteria in a wellcharacterised cohort of COPD patients. We have explored the relationship between airway bacterial prevalence and load in stable COPD patients and at exacerbations. At exacerbation, there was a marked increase in bacterial load in colonised patients, with an absolute increase in the region of 20 -fold being identified in positive samples. We have conclusively demonstrated that qPCR is more discriminatory than culture at detecting typical airway bacteria. The role of atypical pathogens in COPD is minor, having been detected at low prevalence and load in very few samples.

We have found that in the stable state, there is a total prevalence rate for the three typical bacteria-analysed together-of $44.2 \%$. $H$ influenzae was the most prevalent species identified. $H$ influenzae is also the most prevalent species in culture-based studies. $^{4} 20$ The prevalence rate using qPCR in this study was higher than prevalence seen in such culture studies. This work also highlights the association of airway bacteria with a poorer disease outcome in COPD and supports our previous findings, that increased airways inflammation may relate to airway bacterial colonisation ${ }^{5}$ and is associated with faster $\mathrm{FEV}_{1}$ decline. $^{8}$ In the stable state, we found significant correlation between higher bacterial load and more severe airflow limitation, independent of age or smoking status.

One previous study compared detection frequency of typical airway bacteria by qPCR and routine microbiological culture in COPD patients evaluating 30 samples. ${ }^{21}$ In a larger dataset, we have now confirmed that qPCR is significantly more discriminatory than culture at detecting each of these three main airway bacteria. It is known that $H$ influenzae is able to persist intracellularly in the respiratory tract, with possible resultant culture-negative sputum. ${ }^{22}{ }^{23}$ There were some instances in this study where a sample was culture-positive and PCR-negative, and there are a number of potential explanations for this, including technical issues with the primer targets, operator error or sampling, although the rates of such culture-positive PCR- negative samples were actually very low in our study. qPCR is, therefore, the most appropriate method to determine bacterial prevalence and load, with little additional sensitivity to be gained from running both methods in tandem.

The advantage of qPCR is that it gives a higher rate of detection than culture. Using this technique, this study demonstrates that exacerbations in COPD are characteristically associated with both increased prevalence and load of typical bacteria. This confirms previous data suggesting that the increase in load and acquisition of bacteria seen at exacerbation is driving such exacerbations. ${ }^{24}$ Microbiological culture is, however, useful in other aspects of bacteriology, such as in the identification of antibiotic resistance, and so should not be wholly discounted. One limitation of PCR microbiological technique is that they can detect both viable and non-viable bacteria, while culture detects viable bacteria alone. However, to our knowledge, no studies have shown non-viable bacteria to be present at levels of $10^{4} \mathrm{cfu} / \mathrm{ml}$ (the lower limit of detection for our PCR assays). Alveolar macrophages are responsible for clearance of DNA from the lungs, and so it is unlikely that DNA from lysed cells would persist for long periods.

It has also been previously demonstrated that airway bacterial presence is associated with increases in inflammatory cytokines. ${ }^{725} 26$ We have found that bacterial presence at exacerbation detected by PCR is significantly associated with higher systemic inflammation using serum CRP. We also found a trend to increased fall in $\mathrm{FEV}_{1}$ with $\mathrm{HI}$-associated exacerbations, probably due to increased airway inflammation, and this is consistent with our previous data. ${ }^{24}$ Many exacerbations of COPD also have a viral aetiology, and prior studies have demonstrated that exacerbations involving coinfection with bacteria and viruses are associated with a more impaired lung function. ${ }^{24} 27$

We also conclusively quantified typical airway bacteria in a cohort of COPD patients, with a concomitant illustration of significant increases in prevalence and load of three of the most commonly isolated bacteria seen in such subjects, at exacerbation. This provides further support to previous studies which hypothesise that alterations in 'normal' bacterial colonisation may trigger acute exacerbations of COPD. ${ }^{28}$ This study has not examined the strain-switching hypothesis previously put forward. ${ }^{29}$ However, strain acquisition is associated with an increase in bacterial load. Further work is needed to explore whether differences in stable and exacerbation loads are related to the same strain or different strains of specific bacterial species.

For the first time, we have also shown a significant relationship between airway bacterial load and inhaled corticosteroid dosage at the time of sampling in stable patients; this effect was independent of age, smoking status and disease severity. Findings from the TORCH and INSPIRE randomised controlled trials have indicated that inhaled corticosteroid use is related to increased frequency of developing pneumonia in COPD patients. ${ }^{30-32}$ Our data suggests that the increase in airway bacterial colonisation may play a part in increasing susceptibility to pneumonia in COPD.

This study was limited to the three most commonly detected organisms, and it is probable that other organisms also contribute to the microbiome. However, recent detailed studies in small numbers of subjects have identified only the presence of commensals in addition to the common bacteria we studied, and it is unlikely that other bacteria are playing a significant role. $^{28} 3334 P$ aeruginosa was not studied in this analysis as its culture detection rate was very low in the London COPD cohort $(<1 \%)$. It is difficult to differentiate between those strains that were infective and those which were colonising, due to the fact 
that colonising strains are very likely to also appear at exacerbation. The different methodological approaches required are beyond the scope of this study.

The potential role of atypical bacteria in COPD was important to investigate with qPCR, as they are characteristically difficult to culture, and if found at high prevalence or load, could have major implications for therapy. A previous study found little evidence of atypical bacteria colonisation in a qPCR analysis of 248 sputum samples from COPD patients, with just one sample positive for Legionella spp. ${ }^{11}$ The current study investigated the rate of these bacteria in COPD patients and found low prevalence, with one exacerbation sample $(1.3 \%)$ identified with presence of $L$ pneumophila. Atypical bacteria are, therefore, not major pathogens in COPD, either in the stable state or at exacerbation, and do not need specific therapy.

This study shows that at COPD exacerbations, airway bacterial prevalence and load increase significantly, and are an important aetiological factor driving the event. The presence of increased total bacterial load in the stable state and relationship to disease progression suggests that targeted antibiotic therapy for colonised patients may be beneficial. qPCR is more discriminatory than culture, identifying higher airway bacterial prevalence, and thus, should have an important role in routine clinical microbiological practice.

Acknowledgements The authors wish to thank the Medical Research Council (UK) for funding the London COPD cohort and also a capacity-building PhD studentship for D Garcha. We also wish to thank Ray Sapsford for his assistance in rapidly processing sputum samples following collection, and Dr Clare Ling and Julianne Lockwood for their invaluable assistance in multiplex PCR set-up. We are thankful to all patients of the London COPD cohort for dedicating their time and energy to assist others with COPD.

Contributors Study design: DSG, GCD, TDM, JAW; sputum collection and processing: ARCP, AJM, JJPG; data analysis: DSG, GCD; DNA extraction: DSG, SJT; PCR: DSG; manuscript drafting \& revision: DSG, ARCP, AJM, GCD, TDM, JAW; funding: JAW.

Funding This work was supported by Medical Research Council (UK)

Competing interests None.

Ethics approval Ethics approval was provide by Royal Free Research Ethics Committee.

Provenance and peer review Not commissioned; externally peer reviewed.

\section{REFERENCES}

1. Rabe KF, Hurd S, Anzueto A, et al. Global strategy for the diagnosis, management, and prevention of chronic obstructive pulmonary disease: GOLD executive summary. Am J Respir Crit Care Med 2007;176:532-55.

2. Mathers CD, Loncar D. Projections of global mortality and burden of disease from 2002 to 2030. PLoS Med 2006;3:e442.

3. Wedzicha JA, Seemungal TA. COPD exacerbations: defining their cause and prevention. Lancet 2007;370:786-96.

4. Rosell A, Monsó E, Soler N, et al. Microbiologic determinants of exacerbation in chronic obstructive pulmonary disease. Arch Intern Med 2005;165:891-7.

5. Patel IS, Seemungal TA, Wilks M, et al. Relationship between bacterial colonisation and the frequency, character, and severity of COPD exacerbations. Thorax 2002; 57:759-64.

6. Hill AT, Campbell EJ, Hill SL, et al. Association between airway bacterial load and markers of airway inflammation in patients with stable chronic bronchitis. Am J Med 2000;109:288-95

7. Larsen JM, Steen-Jensen DB, Laursen JM, et al. Divergent pro-inflammatory profile of human dendritic cells in response to commensal and pathogenic bacteria associated with the airway microbiota. PLoS One 2012;7:e31976.

8. Wilkinson TM, Patel IS, Wilks M, et al. Airway bacterial load and FEV1 decline in patients with chronic obstructive pulmonary disease. Am J Respir Crit Care Med 2003;167:1090-5
9. Taylor AE, Finney-Hayward TK, Quint JK, et al. Defective macrophage phagocytosis of bacteria in COPD. Eur Respir J 2010;35:1039-47.

10. Miravitlles M, Espinosa C, Fernández-Laso E, et al. Relationship between bacterial flora in sputum and functional impairment in patients with acute exacerbations of COPD*. Chest 1999;116:40-6.

11. Diederen B, van der Valk P, Kluytmans J, et al. The role of atypical respiratory pathogens in exacerbations of chronic obstructive pulmonary disease. Eur Respir $J$ 2007:30:240-4.

12. Lieberman D, Ben-Yaakov M, Lazarovich Z, et al. Chlamydia pneumoniae infection in acute exacerbations of chronic obstructive pulmonary disease: analysis of 250 hospitalizations. Eur J Clin Microbiol Infect Dis

2001:20:698-704.

13. Lieberman D, Lieberman D, Shmarkov 0, et al. Serological evidence of Legionella species infection in acute exacerbation of COPD. Eur Respir $\mathrm{J}$ 2002;19:392-7.

14. Seemungal TA, Donaldson GC, Paul EA, et al. Effect of exacerbation on quality of life in patients with chronic obstructive pulmonary disease. Am J Respir Crit Care Med 1998; 157:1418-22

15. Hurst JR, Donaldson GC, Perera WR, et al. Use of plasma biomarkers at exacerbation of chronic obstructive pulmonary disease. Am J Respir Crit Care Med 2006;174:867-74.

16. Abdeldaim GM, Strålin K, Olcén $\mathrm{P}$, et al. Toward a quantitative DNA-based definition of pneumococcal pneumonia: a comparison of Streptococcus pneumoniae target genes, with special reference to the Spn9802 fragment. Diagn Microbiol Infect Dis 2008;60:143-50.

17. Greiner 0, Day PJ, Altwegg M, et al. Quantitative detection of Moraxella catarrhalis in nasopharyngeal secretions by real-time PCR. J Clin Microbiol 2003:41:1386-90.

18. Nolan T, Hands RE, Ogunkolade W, et al. SPUD: a quantitative PCR assay for the detection of inhibitors in nucleic acid preparations. Anal Biochem 2006:351:308-10

19. Welti M, Jaton K, Altwegg $\mathbf{M}$, et al. Development of a multiplex real-time quantitative PCR assay to detect Chlamydia pneumoniae, Legionella pneumophila and Mycoplasma pneumoniae in respiratory tract secretions. Diagn Microbiol Infect Dis 2003;45:85-95.

20. Monso $\mathbf{E}$, Ruiz J, Rosell A, et al. Bacterial infection in chronic obstructive pulmonary disease. A study of stable and exacerbated outpatients using the protected specimen brush. Am J Respir Crit Care Med 1995;152:1316-20.

21. Curran T, Coyle PV, McManus TE, et al. Evaluation of real-time PCR for the detection and quantification of bacteria in chronic obstructive pulmonary disease. FEMS Immunol Med Microbiol 2007;50:112-18.

22. Salcedo SP, Cid VJ. Nontypable Haemophilus influenzae: an intracellular phase within epithelial cells might contribute to persistence. Microbiology 2011;157:1-2

23. Murphy TF, Brauer AL, Schiffmacher AT, et al. Persistent colonization by haemophilus influenzae in chronic obstructive pulmonary disease. Am J Respir Crit Care Med 2004:170:266-72.

24. Wilkinson TM, Hurst JR, Perera WR, et al. Effect of interactions between lower airway bacterial and rhinoviral infection in exacerbations of COPD*. Chest 2006:129:317-24.

25. White AJ, Gompertz S, Bayley DL, et al. Resolution of bronchial inflammation is related to bacterial eradication following treatment of exacerbations of chronic bronchitis. Thorax 2003:58:680-5.

26. Daniels JM, Schoorl M, Snijders D, et al. Procalcitonin vs C-reactive protein as predictive markers of response to antibiotic therapy in acute exacerbations of COPD. Chest 2010:138:1108-15.

27. Papi A, Bellettato CM, Braccioni F, et al. Infections and airway inflammation in chronic obstructive pulmonary disease severe exacerbations. Am J Respir Crit Care Med 2006;173:1114-21.

28. Huang YJ, Kim E, Cox MJ, et al. A Persistent and Diverse airway microbiota present during chronic obstructive pulmonary disease exacerbations. OMICS 2010;14:9-59

29. Sethi S, Evans N, Grant BJ, et al. New strains of bacteria and exacerbations of chronic obstructive pulmonary disease. N Engl J Med 2002;347:465-71.

30. Calverley PM, Anderson JA, Celli B, et al. Salmeterol and fluticasone propionate and survival in chronic obstructive pulmonary disease. N Engl J Med 2007:356:775-89.

31. Wedzicha JA, Calverley PM, Seemungal TA, et al. The prevention of chronic obstructive pulmonary disease exacerbations by salmeterol/fluticasone propionate or tiotropium bromide. Am J Respir Crit Care Med 2008;177:19-26.

32. Calverley PM, Stockley RA, Seemungal TA, et al. Reported pneumonia in patients with COPD: findings from the INSPIRE study. Chest 2011;139:505-12.

33. Erb-Downward JR, Thompson DL, Han MK, et al. Analysis of the lung microbiome in the "Healthy" Smoker and in COPD. PLoS One 2011:6:e16384.

34. Hilty $\mathbf{M}$, Burke $\mathrm{C}$, Pedro $\mathrm{H}$, et al. Disordered microbial communities in asthmatic airways. PLoS One 2010;5:e8578. 